\title{
Cognitive and Behavioral Effects of Participatory Sex Education on the Dual Prevention of STI/HIV/AIDS and Unwanted Pregnancies among Adolescents in Kinshasa High Schools, DR Congo
}

\author{
Gabriel Vodiena Nsakala ${ }^{1,2^{*}}$, Yves Coppieters ${ }^{2}$, Patrick Kalambayi Kayembe ${ }^{3}$ \\ ${ }^{1}$ "Carnet de santé asbl", Communication Research and Health Promotion, Kinshasa, Democratic Republic of \\ Congo \\ ${ }^{2}$ Research Centre "Policies and Health Systems-International Health", School of Public Health, Université \\ Libre de Bruxelles (ULB), Brussels, Belgium \\ ${ }^{3}$ Department of Epidemiology and Bio Statistics, School of Public Health, University of Kinshasa, Kinshasa, \\ Democratic Republic of Congo \\ Email: "gabysak@yahoo.fr
}

Received 21 December 2013; revised 22 February 2014; accepted 2 April 2014

Copyright (C) 2014 by authors and Scientific Research Publishing Inc.

This work is licensed under the Creative Commons Attribution International License (CC BY).

http://creativecommons.org/licenses/by/4.0/

(c) (i) Open Access

\begin{abstract}
Context: With the view to reorient both STI/HIV/AIDS prevention and adolescents pregnancies, this research study aims at evaluating cognitive and behavioral acquisitions, as well as the process of interactive sex education participatory approach among adolescents in Kinshasa high schools. Methods: Based on a "pre and post" virtually experimental design, two crosswise surveys were conducted in Kinshasa, for six months in 2011-2012 on 484 high school students (pre-survey) and on 441 high school students (post-survey), whose age range from 14 - 19 years including both sexes. Two participatory educational talks (PET) "A" and "B", covered weekly in two different schools, were compared to a control group school. The PET " $A$ " consisted of interactive interpersonal communication sessions given by an external expert as a substitute for the life education course in one school. The PET "B" carried out in another school, included more educational talk sessions, led by the external expert and supplemented by a close follow-up of teenagers divided into small groups of 10 participants. The subjects' assessment was based on their knowledge, attitudes and practices relating to STI/HIV/AIDS dual prevention as well as to unwanted pregnancies. Results: The subjects involved in the PET "B" displayed a better/higher performance based on
\end{abstract}

"Corresponding author.

How to cite this paper: Nsakala, G.V., et al. (2014) Cognitive and Behavioral Effects of Participatory Sex Education on the Dual Prevention of STI/HIV/AIDS and Unwanted Pregnancies among Adolescents in Kinshasa High Schools, DR Congo. Open Journal of Preventive Medicine, 4, 204-215. http://dx.doi.org/10.4236/ojpm.2014.44026 
their knowledge, attitudes and practices related to STI/HIV/AIDS dual prevention and unwanted pregnancies. Broadly speaking, knowledge has been improved 6 times with the PET "B" $(O R=6,10$, IC 95\%) (3.24 - 11.9), and 3 times with the PET "A" $(O R=3,45$, IC 95\%) (1.79 - 6.81), compared to control school. Similarly, findings on subjects' attitudes show an improvement rated 12 times with the PET"B" (OR = 11, 99, IC 95\%) (5.67 - 27.38) and 5 times for the PET "A" (OR = 5.51, IC 95\%) $(2.54$ - 12.87). As far as the subjects' practices are concerned, an improvement of 6 more times of protected sexual intercourses with the PET " $B$ " compared with the control school group $(0 R=6$, 52, IC 95\%) (3.60 - 12.0). The process assessment records a spontaneous involvement of schools enhanced by the positive contribution of Life Education and Biology teachers; add a massive participation of adolescents who requested permanent PET program. Conclusion: The results of this study suggest that school sexual education programs can be improved to increase the quality of apprenticeship. The use of interactive methods and the consideration of the adolescents' specific needs that take into account the gender approach may bring about beneficial advantages on both educational outcomes and reproductive health of adolescents.

\section{Keywords}

Cognitive and Behavioral Effects; Sex Education; STI/HIV/AIDS; Unwanted Pregnancies; Adolescents; DRC

\section{Introduction}

On the eve of the 2015 Millennium Development Goals, the African region is still suffering a high prevalence of HIV, an increased number of children and young people living with HIV, new infections among the young, high rates of unwanted pregnancies and other needs with no response as regard sexual and reproductive health [1]. In the DRC, the overall population HIV prevalence is estimated at $2.6 \%$; and at $3 \%$ specifically for young people (15 - 24 years) [2]. The estimated $28.4 \%$ of teenage pregnancies [3] is partly due to the early onset of sexual activity. Indeed, $21.4 \%$ of girls first had sexual intercourses before the age of 15 , with an average age range of 16.8 at the first sexual intercourses for females; and 17.9 years for males [4]. Although such median ages at the first sexual intercourses are the lowest in Francophone Africa, 15 - 19-year-old youths in the DRC are among the most sexually active in the region (18\% of boys and $17.9 \%$ of girls) but with an extremely low condom use ratio during the first sexual intercourses ( $8.9 \%$ for boys and $5.6 \%$ for girls) [5]. Moreover, knowledge of detailed information on HIV is also very low among young people; and the proportion of young men and women aged 15 - 24 years with comprehensive correct knowledge of HIV is 15\% for women and 21\% for men [4]. Throughout the past decade, these risk and vulnerability factors were unevenly rated, due to socio-demographic (age, sex, education) and environmental factors (urban and rural residence) among adolescents [6]. In urban areas, intense sexual activity among young people essentially stems from erotic needs and material concerns [7]. Likewise, issues concerning emotional relationships and sexual practices, along with other ones which are considered more gender-based, particularly concern girls (menstrual cycle disorders, virginity) and boys (masturbation, penis size) [8]. Youths and adolescents request sex education under the guidance of trustworthy actors acting confidentially [7]. So, this overview of sexual and reproductive health for young people and teenagers in the DRC calls for strategies bearing effects and beneficial outcomes that are observable and measurable, taking into account their socio-environmental categories. In this context, sex education and HIV prevention need to be developed for young people and teenagers in an innovative approach that considers boys' and girls' specific needs. In the DRC, the family life education course which is theoretically part of the primary and secondary school curricula [9], does not yet have a formal program. Such lack is compensated by life education programs proposed for the Central Service for Life Education SCEV, which is a catholic organization [10]. Policy program design is based on moral values and masks some considerations of the emotional lives of young people such as condom promotion. Sex education is defined as a way of teaching sexuality and interpersonal relationships which are adapted to age, culturally relevant, and based on accurate, realistic and scientific information, which is free from value judgment [11]. It has met the international organizations consensus. The latter have defined the key principles underlying their integration within the country as a prospect for the prevention of HIV/AIDS and of health and reproductive 
problems among young people [11].

With regard to the DRC, such a program set up in schools would require a follow up, support and thorough assessment both at the level of the process and of its purpose. In the end, this assessment must measure pupils' performances as regards knowledge, attitudes, and practices in connection with the dual prevention of STI/HIV/ AIDS and unwanted pregnancies, as the resultant acquisitions of topics covered in the current program of life's education course.

This research objective aims, on one hand, to determine the cognitive effects and behavioral acquisitions of the training activity, and on the other, to describe the evaluation of the process of a participatory approach to sex education among teens in Kinshasa high schools.

\section{Methodology}

\subsection{Type and Framework of the Study}

This is a "pre and post", quasi experimental study carried out between September 2011 and February 2012 on pupils from three schools of Kinshasa-West educational province. This quasi experimental research is based on a comparison of two similar groups, but whose selection criteria were not done at random [12]. The approach contrasts the experimental and control groups. These two groups must have similar characteristics to those of the participants. In the case of this study, two types of interventions (participatory educational talks "PET") were compared to a control group, since the aim of this research study is to prove that the changes observed would really stem from the effects of the interventions (PET) rather than from external elements.

\subsection{Choice and Selection of Schools}

The study was carried out in Kinshasa, DRC, high schools where the base unit was the educational province. Based on their affiliation (state-owned, church-owned, or private), a school was selected at random from a list of Kinshasa-West educational province schools. In each school, all 14 - 19-year-old pupils-boys and girls-were eligible to take part in the study. Two variants of the interventions (PET) were proposed to two schools under the state and private systems respectively, and were compared with a control school. In schools, interventions (PET) were organized in accordance with the manner in which the sex education program is considered. Interventions (participatory educational talks) referred to as "A" and "B" were offered to public and private schools where life education course is taught on a random basis, while the control school was a Catholic establishment where life education program follows the SCEV program.

\subsection{Data Collection Method}

At the start and at the end of the interventions (PET), two cross-sectional quantitative surveys with the same questionnaire were used to collect data. In both situations, this questionnaire was collectively administered by the Researcher to groups of pupils in their respective classrooms. Included were 14 - 19-year-old male and female pupils from the $3^{\text {rd }}$ and $5^{\text {th }}$ forms of all streams. Before the intervention (PET), the questionnaire was pre-tested in two schools other than those sampled for the survey on eighty 15 - 19-year-old pupils from all school levels. This allowed measuring the acceptance level, duration and comprehension of questions by pupils.

\subsection{Description of Interventions}

The intervention (PET) "A" consisted of having pupils from a school (state-owned) benefit from interactive interpersonal communication sessions given by an external expert as a substitute for the life education course. The intervention (PET) "B" was carried out in another school (private). It included more educational talk sessions, led by the external expert and supplemented by a close follow-up of teenagers divided into small groups of 10 participants. The Catholic school, that served as comparison group only benefited from Life education course with the local teacher with whom the PET was delivered. In the three schools, sessions were organized following the same timetable, i.e. 45 minutes per week per level for six months. A pedagogic guideline designed on the basis of the needs expressed by teenagers through their participation in the interactive radiophonics programs via sms [8], was used as didactic support for both interventions PET “A" and "B". Designed in accordance with the thematic progression, this guideline has selected these main topics: puberty and its implications on the emotional life, the men- 
strual cycle, STIs, HIV/AIDS and intimate hygiene. These themes are also part of the lessons contained in the SCEV's live education.

With the control group school, the teacher used the family life program designed by the SCEV. Her teaching activities followed the same timetable distribution as that of the two intervention schools (PET). Assessment was based on knowledge related to HIV/AIDS prevention, STI symptoms, menses cycle; to attitudes relating to HIV test, dialogue with parents on STI questions, HIV/AIDS or pregnancies; and to practices relating to intercourse and condom use.

The two pre and post cross-sectional surveys helped to assess the effect of these two intervention approaches, on compared to the control group.

The characteristics of the various interventions (PET) are shown in Table 1.

\subsection{Intervention Assessment}

The intervention (PET) used in this study took place over six months and were evaluated according to two main aspects: their development, which refers to a formative assessment (or of the process) and their outcomes or results referred to as summative assessment [13].

Pupils' active participation, the relevance of questions, and concerns during sessions, and pupils' reactions which served as follow-up indicators, were indicative of the adhesion of the target audience to the program. The analysis of the contents of written documents (attendance register, teacher's dairy, lesson plans...), the interview with teachers and satisfaction assessment in small groups, were used as data sources to follow up the implementation of the program during the formative evaluation. As for the summative assessment, it takes into account the results of the various components of knowledge, attitudes and practices recorded before and after from the three study schools. Operationally, the study protocol paid much attention to the "program load" for the first two schools and for the third one as well. Indeed, the program load is measured in terms of frequency, duration, as well as of intensity and refers to the exposure of an individual to communication intervention [14]. Links with the observed changes were analyzed, because it is clear that the higher the load, the greater the chances of behavioral change.

\subsection{Data Analysis}

\subsubsection{Studied/Observed Variables}

In order to facilitate the assessment of the observed effects, groups of variables were created by merging simple variables in order to assess the knowledge, attitudes, and practices associated with the dual prevention of IST/ HIV/AIDS and unwanted pregnancies. These are: 1) the knowledge variable combining three components (knowledge of at least three signs of STIs, knowledge of the three prevention modes of HIV/AIDS, knowledge

Table 1. Description of the components of interventions in three secondary schools in Kinshasa (September 2011-February 2012).

\begin{tabular}{|c|c|c|c|c|c|}
\hline $\begin{array}{c}\text { Type of } \\
\text { intervention }\end{array}$ & $\begin{array}{c}\text { Nature of } \\
\text { intervention }\end{array}$ & $\begin{array}{l}\text { Frequency, duration and } \\
\text { educational materials }\end{array}$ & Facilitator's profile & $\begin{array}{l}\text { Targets of the } \\
\text { intervention }\end{array}$ & $\begin{array}{c}\text { Elements for evaluating } \\
\text { interventions }\end{array}$ \\
\hline $\begin{array}{l}\text { Intervention } \\
\text { "A" }\end{array}$ & $\begin{array}{c}\text { Participatory } \\
\text { educational } \\
\text { talks (PET) }\end{array}$ & $\begin{array}{l}\text { Frequency and duration: } 5 \times 2 \\
\text { 45-minute sessions for } 6 \text { months } \\
\text { Material: A guide developed } \\
\text { based on the needs expressed }\end{array}$ & $\begin{array}{l}\text { An external expert } \\
\text { from outside the } \\
\text { school, specializing } \\
\text { in adolescent health }\end{array}$ & $\begin{array}{l}\text { Students aged } \\
14 \text { - } 19 \text { attending } \\
\text { a public school }\end{array}$ & $\begin{array}{l}\text { Knowledge, Attitudes } \\
\text { and practices of } \\
\text { students in connection } \\
\text { with the topics }\end{array}$ \\
\hline $\begin{array}{l}\text { Intervention } \\
\text { "B" }\end{array}$ & $\begin{array}{l}\text { Participatory and } \\
\text { educational talks } \\
\text { (PET) followed } \\
\text { by discussions } \\
\text { in small groups } \\
\text { of } 10 \text { participants }\end{array}$ & $\begin{array}{c}\text { Frequency and duration: } 5 \times 2 \\
\text { 45-minute sessions for } 6 \text { months } \\
\text { Material: A guide developed } \\
\text { based on the needs expressed }\end{array}$ & $\begin{array}{l}\text { An external expert } \\
\text { from outside the } \\
\text { school, specializing } \\
\text { in adolescent health }\end{array}$ & $\begin{array}{c}\text { Students aged } \\
14 \text { - } 19 \text { attending } \\
\text { a private school }\end{array}$ & $\begin{array}{l}\text { Knowledge, Attitudes } \\
\text { and practices of } \\
\text { students in connection } \\
\text { with the topics }\end{array}$ \\
\hline "Control" & $\begin{array}{l}\text { Life education } \\
\text { lecture }\end{array}$ & $\begin{array}{l}\text { Frequency and duration: } 5 \times 2 \\
\text { 45-minute sessions for } 6 \text { months } \\
\text { Material: Life education } \\
\text { syllabus developed by the central } \\
\text { life education service }\end{array}$ & $\begin{array}{c}\text { School teacher, } \\
\text { qualified life education } \\
\text { teacher, previously } \\
\text { trained by the central } \\
\text { life education service }\end{array}$ & $\begin{array}{c}\text { Students aged } \\
15 \text { - } 19 \text { attending } \\
\text { a Catholic school }\end{array}$ & $\begin{array}{l}\text { Knowledge, attitudes } \\
\text { and practices related } \\
\text { to course topics } \\
\text { discussed }\end{array}$ \\
\hline
\end{tabular}


of pregnancy prevention using the menstrual calendar); 2) attitude variable with two components (to talk with parents on HIV/STIs and pregnancy issues, to be favorable to HIV test); and 3) practice variable with its two components (having had sex in the past 3 months and having used a condom when doing so). Then, score variables were built from knowledge, attitudes, or practices variables. So, 1) the "knowledge score" variable includes those who have no knowledge, those who have an excellent knowledge in a field, in two fields, or in all three areas assessed (STIs, HIV, pregnancy) best knowledge score; 2) the "attitude score" variable includes those who have no good attitude, who are favorable to the HIV test or to dialogue with parents; and those who are favorable to both (HIV test and dialogue with parents = best attitude score; 3) the "practice score" includes those who have had unprotected sex, both those who have not had sex and those who have had protected sex = best practice score.

\subsubsection{Measure of Intervention (PET) Effects}

Originally encoded on Epi Info 6, "pré" and "post” data were respectively converted to SPSS version 15. The usual statistics were generated and analyses were done on a comparative basis: on the one hand, between the schools before the intervention (PET), and on the other, depending on the type of intervention (PET) compared to the control group. The differential spread/variance between schools before the intervention (PET) was taken into account. The chi-square test was used to determine the associations between categorical variables. Associations between variables were sought and the calculation of the odds ratio is used as a measure of epidemiological association with confidence interval (CI) $95 \%$. The threshold of $0.05 \%$ was considered to be significant.

\subsection{Ethical Considerations}

We obtained informed, free, oral consent from students before administering the questionnaire. The information collected was anonymous and any information related to the identity of interviewees was confidential. However, the research protocol as well as survey questionnaire were approved by the Research Ethics Committee of Kinshasa School of Public Health.

\section{Results}

\subsection{Socio-Demographic Description of the Sample}

The profile of the sample that took part before and after the intervention (PET) in the three schools is shown in Table 2.

An almost homogeneous distribution of the sample can be seen, providing good data comparability. Initially, 484 pupils out of a total of 500 targeted took part in the intervention (PET), i.e. a participation rate of $96.8 \%$. Participation per school was $35.5 \%$ for school A, 31.6\% for school B, and 32.9\% for the control group school.

Table 2. Sociodemographic profile of the participants before and after the intervention in the three schools (September 2011-February 2012).

\begin{tabular}{|c|c|c|c|c|c|c|c|c|}
\hline \multirow{2}{*}{ Variables } & \multicolumn{4}{|c|}{ Before $(\mathrm{N}=484)$} & \multicolumn{4}{|c|}{ After $(\mathrm{N}=441)$} \\
\hline & $\begin{array}{c}\text { School A } \\
\text { N (\%) }\end{array}$ & $\begin{array}{c}\text { School B } \\
\text { N (\%) }\end{array}$ & $\begin{array}{c}\text { Control } \\
\text { N (\%) }\end{array}$ & $\begin{array}{c}\text { Total } \\
\text { N (\%) }\end{array}$ & $\begin{array}{c}\text { School A } \\
\text { N (\%) }\end{array}$ & $\begin{array}{c}\text { School B } \\
\text { N (\%) }\end{array}$ & $\begin{array}{l}\text { Control } \\
\text { N (\%) }\end{array}$ & $\begin{array}{c}\text { Total } \\
\text { N (\%) }\end{array}$ \\
\hline \multicolumn{9}{|l|}{ Age } \\
\hline 15 - 19 years & 172 (35.5) & 153 (31.6) & 159 (32.9) & $484(100)$ & 149 (33.7) & $143(32.4)$ & 149 (33.7) & 441 (100) \\
\hline \multicolumn{9}{|l|}{ Sex } \\
\hline Boys & 67 (13.8) & 62 (12.8) & 78 (16.2) & 207 (42.8) & 59 (13.3) & 57 (12.9) & 73 (16.5) & 189 (42.8) \\
\hline Girls & 105 (21.6) & 91 (18.8) & 81 (16.8) & 277 (57.2) & 96 (21.7) & 89 (20.1) & 78 (17.6) & $252(57.2)$ \\
\hline \multicolumn{9}{|l|}{ Sectors } \\
\hline Sciences & $55(32.0)$ & 34 (22.2) & 37 (23.3) & $126(26.0)$ & 50 (33.6) & 28 (19.6) & 44 (33.1) & 122 (28.7) \\
\hline Commercial & $42(24.4)$ & $40(26.1)$ & 45 (28.3) & $127(26.2)$ & 37 (24.8) & 25 (17.5) & $16(12.0)$ & 78 (18.4) \\
\hline Literature & 75 (43.6) & 79 (51.6) & 77 (48.4) & $231(47.7)$ & $62(41.6)$ & 90 (62.9) & 73 (54.9) & 225 (52.9) \\
\hline
\end{tabular}


At the end of the intervention (PET), the control was done on 441 pupils (33.7\% for A, 32.4\% for B, and 33.7\% for the control group school. The number of program drop outs is less than $10 \%$, i.e. 43 out of 484.

\subsection{Summative Assessment}

Results for different components of knowledge, practices, and attitudes are shown in various tables.

Table 3 shows a comparative description of pupils' knowledge, attitudes, and practices per schools before and after the intervention (PET).

Table 3. A comparative description of pupils' knowledge, attitudes, and practices as per the different schools before and after the intervention (September 2011-February 2012).

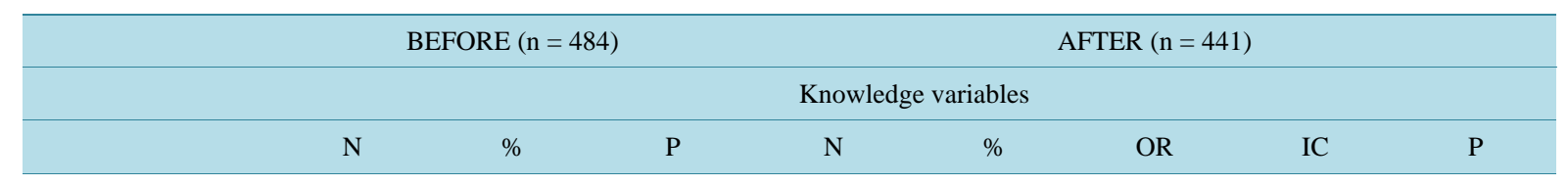

Knowledge of at least three signs of STIs

\begin{tabular}{|c|c|c|c|c|c|c|c|}
\hline Control & 159 & 34.6 & & 149 & 36.9 & 1 & \\
\hline Intervention A & 153 & 32.0 & 0.890 & 143 & 44.8 & 1.38 & $0.84-2.27$ \\
\hline Intervention B & 172 & 35.1 & & 149 & 64.4 & 3.10 & $1.87-5$. \\
\hline
\end{tabular}

Knowledge of the three prevention modes of HIV/AIDS

\begin{tabular}{|c|c|c|c|c|c|c|c|c|}
\hline Control & 159 & 36.5 & 0.589 & 149 & 39.6 & 1 & & 0.000 \\
\hline Intervention A & 153 & 39.2 & & 143 & 76.2 & 4.90 & $2.87-8.40$ & \\
\hline Intervention B & 172 & 33.7 & & 149 & 79.8 & 6.05 & $3.50-10.53$ & \\
\hline \multicolumn{9}{|c|}{ Knowledge of pregnancy prevention using the menstrual calendar } \\
\hline Control & 159 & 64.2 & 0.918 & 149 & 65.1 & 1 & & 0.012 \\
\hline Intervention A & 153 & 64.1 & & 143 & $76 . .2$ & 1.71 & $0.99-2.97$ & \\
\hline Intervention B & 172 & 62.2 & & 149 & 79.7 & 2.11 & $1.21-3.70$ & \\
\hline \multicolumn{9}{|c|}{ Attitudes variables } \\
\hline \multicolumn{9}{|c|}{ Be favorable to do the HIV test } \\
\hline Control & 159 & 49.0 & 0.645 & 142 & 50.3 & 1 & & 0.000 \\
\hline Intervention A & 153 & 49.0 & & 141 & 61.8 & 1.58 & $0.97-2.60$ & \\
\hline Intervention B & 172 & 53.0 & & 149 & 73.2 & 2.68 & $1.61-4.4$ & \\
\hline \multicolumn{9}{|c|}{ Dialogue with parents on HIV/STIs and pregnancy issues } \\
\hline Control & 159 & 14.8 & 0.000 & 159 & 12.6 & 1 & & 0.000 \\
\hline Intervention A & 153 & 50.9 & & 153 & 44.0 & 5.38 & $2.91-10.20$ & \\
\hline Intervention B & 172 & 50.6 & & 172 & 63.1 & 11.7 & $6.31-22.14$ & \\
\hline \multicolumn{9}{|c|}{ Practice variables } \\
\hline \multicolumn{9}{|c|}{ Having no had sex in the past 3 months } \\
\hline Control & 159 & 64.2 & 0.202 & 149 & 37.6 & 1 & & 0.000 \\
\hline Intervention A & 153 & 64.1 & & 143 & 42.7 & 1.23 & $0.75-2.03$ & \\
\hline Intervention B & 172 & 72.1 & & 149 & 69.8 & 3.84 & $2.31-6.40$ & \\
\hline \multicolumn{9}{|c|}{ Having had protected sex with condom use } \\
\hline Control & 43 & 25.6 & 0.182 & 71 & 22.5 & 1 & & 0.003 \\
\hline Intervention A & 55 & 43.6 & & 82 & 37.8 & 2.10 & $0.97-4.59$ & \\
\hline Intervention $\mathrm{B}$ & 48 & 35.4 & & 45 & 53.3 & 3.93 & $1.63-9.56$ & \\
\hline
\end{tabular}


Previously, there were no differences between pupils' knowledge, attitudes and practices according to schools, except for the fact that there are more school children in both intervention (PET) "A and B" schools who engaged in dialogue with parents, compared to the control group school. It should be noted that in the three schools, there was a low awareness on the signs of STIs and HIV prevention methods before the intervention (PET). Compared with the control school, this poor performance was significantly improved by the interventions in both schools "A and B".

After the interventions (PET), students' knowledge, attitudes, and practices generally varied according to the school.

Table 4 shows the measure of the effect of various interventions (PET) on the best score of knowledge, attitudes, and practices in the different schools.

Whether knowledge, attitudes or practices, the best score is attained by intervention " $\mathrm{B}$ " for each of the components of each variable.

Everything considered, knowledge favoring STI/HIV/pregnancy prevention is improved 6 times by intervenetion "B", and three times by intervention " $\mathrm{A}$ ", compared to the control school. It is the same for attitudes, which are improved 12 times (intervention B) and 5 times for intervention A. As for practices, intervention B beneficiaries had 6 times more protected sex compared to control group schools.

Table 5 reports the global effect of different types of interventions on the pupils' knowledge, attitudes, and practices of STI/HIV/pregnancy prevention in the two schools compared to the control group school.

In general, intervention " $\mathrm{B}$ " provides a better increase in knowledge of STI signs compared to intervention "A", and an obvious improvement in the 3 modes of preventing HIV and avoiding pregnancy through the menstrual cycle compared to the control group school.

On the other hand, interventions (PET) “A and B” have visibly improved sexual attitudes and practices—-with an increase in condom use in favor of intervention "B".

\subsection{Formative Assessment}

\subsubsection{Schools' Involvement in the Process}

Schools spontaneously took part in the survey after they were informed of the research purpose and stakes. As a sign of the acceptance of the project by the schools, the researcher (External expert) joined the teaching team and was allocated a workspace in the two intervention sites. Schedules were arranged according to the intervention; although the slots of some subjects were assigned to facilitate the intervention. The number of sessions

Table 4. Measure of the effect of various interventions on the best score of knowledge, attitudes, and practices in the different schools (September 2011-February 2012).

\begin{tabular}{|c|c|c|c|c|c|c|c|c|}
\hline & \multicolumn{3}{|c|}{ BEFORE $(n=484)$} & \multicolumn{5}{|c|}{$\operatorname{AFTER}(n=441)$} \\
\hline & $\mathrm{N}$ & $\%$ & $\mathrm{P}$ & $\mathrm{N}$ & $\%$ & OR & IC & $\mathrm{P}$ \\
\hline \multicolumn{9}{|c|}{ Best knowledge score (all three areas assessed STIs, HIV, pregnancy) } \\
\hline Control & 159 & 12.6 & 0.185 & 149 & 11.4 & 1 & & 0.000 \\
\hline Intervention A & 153 & 6.5 & & 143 & 30.7 & 3.45 & $1.79-6.81$ & \\
\hline Intervention B & 172 & 11.1 & & 149 & 43.9 & 6.10 & $3.24-11.9$ & \\
\hline \multicolumn{9}{|c|}{ Best attitude score (are favorable to both: HIV test and dialogue with parents) } \\
\hline Control & 159 & 7.55 & 0.000 & 136 & 6.7 & 1 & & 0.000 \\
\hline Intervention A & 153 & 26.80 & & 136 & 26.4 & 5.51 & $2.54-12.87$ & \\
\hline Intervention B & 172 & 27.33 & & 142 & 46.3 & 11.99 & $5.67-27.38$ & \\
\hline \multicolumn{9}{|c|}{ Best practice score (those who have not had sex and have had protected sex with condom use) } \\
\hline Control & 159 & 71.7 & 0.064 & 149 & 48.3 & 1 & & 0.000 \\
\hline Intervention A & 153 & 79.7 & & 143 & 64.3 & 1.92 & $1.17-3.17$ & \\
\hline Intervention B & 172 & 82.0 & & 149 & 85.9 & 6.52 & $3.60-12.0$ & \\
\hline
\end{tabular}


Table 5. Global effect of different types of interventions on the pupils' knowledge, attitudes, and practices of dual STI/ HIV/and pregnancy prevention in the two schools compared to the control school (September 2011-February 2012).

\begin{tabular}{|c|c|c|c|c|c|c|c|c|c|c|c|c|}
\hline \multirow[b]{2}{*}{$\begin{array}{c}\text { Type of } \\
\text { Intervention }\end{array}$} & & \multirow[b]{2}{*}{$\mathrm{n}$} & \multicolumn{3}{|c|}{ Knowledge variables \% } & \multicolumn{2}{|c|}{ Attitudes variables $\%$} & \multicolumn{2}{|c|}{ Practice variable \% } & \multicolumn{3}{|c|}{ Best scores variables \% } \\
\hline & & & $\begin{array}{l}\text { At least } \\
\text { three } \\
\text { signs of } \\
\text { STI }\end{array}$ & $\begin{array}{l}\text { The three } \\
\text { prevention } \\
\text { modes of } \\
\text { HIV/AIDS }\end{array}$ & $\begin{array}{c}\text { Pregnancy } \\
\text { prevention } \\
\text { using } \\
\text { menstrual } \\
\text { calendar }\end{array}$ & $\begin{array}{l}\text { Favorable } \\
\text { to do the } \\
\text { HIV test }\end{array}$ & $\begin{array}{l}\text { Dialogue } \\
\text { with the } \\
\text { parents }\end{array}$ & $\begin{array}{l}\text { No had } \\
\text { sex in the } \\
\text { past three } \\
\text { months }\end{array}$ & $\begin{array}{c}\text { Had } \\
\text { protected } \\
\text { sex with } \\
\text { condom } \\
\text { use }^{* *}\end{array}$ & $\begin{array}{l}\text { Knowledge } \\
\text { Score }\end{array}$ & $\begin{array}{l}\text { Attitude } \\
\text { Score }\end{array}$ & $\begin{array}{l}\text { Practice } \\
\text { Score }\end{array}$ \\
\hline \multirow{4}{*}{ Control } & Before & 159 & 36.5 & 56.8 & 64.2 & 49.1 & 13.8 & 64.2 & 21.1 & 12.6 & 7.6 & 71.7 \\
\hline & After & 149 & 39.6 & 53.2 & 65.1 & 50.3 & 12.8 & 37.6 & 17.2 & 11.4 & 6.7 & 48.3 \\
\hline & $\pi 1-\pi 2^{*}$ & & 3.1 & -3.6 & 0.9 & 1.2 & -1 & -26.6 & -3.9 & -1.2 & -0.9 & -23.4 \\
\hline & $\mathrm{P}$ value & & 0.573 & 0.671 & 0.862 & 0.822 & 0.779 & 0.000 & 0.557 & 0.752 & 0.776 & 0.000 \\
\hline \multirow{4}{*}{$\begin{array}{l}\text { Intervention } \\
\text { "A" }\end{array}$} & Before & 153 & 39.2 & 32 & 64.5 & 49 & 51 & 64.1 & 43.6 & 6.5 & 26.8 & 79.7 \\
\hline & After & 143 & 76.2 & 44.8 & 76.2 & 61.7 & 44.1 & 42.7 & 37.8 & 30.8 & 28.4 & 64.3 \\
\hline & $\pi 1-\pi 2$ & & 37 & 12.8 & 11.7 & 12.7 & -6.9 & -21.4 & -5.8 & 24.3 & 1.6 & -15.4 \\
\hline & $\mathrm{P}$ value & & 0.000 & 0.024 & 0.022 & 0.029 & 0.233 & 0.000 & 0.495 & 0.000 & 0.763 & 0.003 \\
\hline \multirow{4}{*}{$\begin{array}{l}\text { Intervention } \\
\text { "B" }\end{array}$} & Before & 172 & 33.7 & 33.1 & 62.1 & 53.5 & 50.6 & 72.1 & 35.4 & 11.1 & 27.3 & 82.0 \\
\hline & After & 148 & 79.9 & 64.4 & 79.7 & 73.2 & 63.1 & 69.8 & 56.5 & 43.9 & 46.3 & 85.9 \\
\hline & $\pi 1-\pi 2$ & & 46.2 & 31.3 & 17.6 & 19.7 & 12.5 & -2.3 & 21.1 & 32.8 & 19 & -0.3 \\
\hline & $P$ value & & 0.000 & 0.000 & 0.001 & 0.000 & 0.024 & 0.651 & 0.04 & 0.000 & 0.000 & 0.908 \\
\hline
\end{tabular}

** The "protected sex" variable was not calculated on all individuals, but on students who reported having had sexual intercourse. The "n" are respectively 43, 55, 48 before and 71, 82, 45 after intervention. ${ }^{*} \pi 1-\pi 2$ expresses the difference between post-proportion and pré-proportion.

planned for each level of study and each school were accomplished. Some sessions were considered very short, due to both relevance of the subjects addressed and participants' interest. Biology and life education teachers particularly cooperated. They were highly active in the organization of educational sessions. As the "post” phase intervention occurred at the end of the semester, an a posteriori request was made by the head of school B in order to consider the survey data as students’ semi-annual marks.

\subsubsection{Acceptance of the Program by Participants}

Having explained the research purpose, admission to the program was free and voluntary. The majority of teenagers appreciated the initiative and played an active role in the educational sessions. Participants' interest regarding all the subjects was evident. Thus, they expressed a desire for the process to be permanent. Participants addressed sexuality issues without embarrassment. Girls more than boys, posed a lot of questions related to certain practices identified among the youth community.

In school "A", pupils completing 6th form who were excluded from the program in the initial phase requested to take part in it. Thus, they were given one session outside the context of the intervention, with the collaboration of biology teacher who offered two slots of the course.

\section{Discussion}

This survey was devoted to the evaluation of both the process and the effects of an interactive sex education program in Kinshasa schools. It shows overall positive outcomes of comprehensive sex education on knowledge, attitudes and practices compared to the teaching of the life education course as delivered to students in their schools.

However, carried out in DRC urban areas, the survey certainly has its limits. Developed on an experimental basis, it only involved three schools out of the hundreds of school in Kinshasa City. Given that the majority of Congolese live in rural areas, the study carried out in an area of the capital on school children cannot expect to 
have an impact on the entire youth population of the country. This is due to the fact that in the DRC, not all adolescents have access to education [4]. Still, considering the methodologically rigorous design whose internal and external validities are ensured, the results obtained can basically serve as a foundation to establish guidelines and implement the program on a large scale.

\subsection{On the Choice of Evaluation Types for the Intervention}

Two concepts coexist as regard the evaluation of health interventions; each is justified by the type of approach used in the program [15]. The first school uses the experimental method which is based on epidemiological data and which compares two different populations. It aims at measuring the program's effects: improved knowledge, skills, attitudes, and health behaviors. It advocates a scientifically determined efficiency from quantitative indicators. The second school stresses the evaluation of the process, i.e. the fine piloting of the actions carried out, especially by qualitative evaluations allowing, not measuring a change, but understanding how the program was applied, understood, experienced and accepted. It rather advocates a democratically determined efficiency, i.e. by a jury comprising funders, public, participants and experts [15]. If the first approach is said to be a traditional positivist one and covers the field of health education, the second is postmodern and pertains to health promotion [16]. The combination of these two approaches in this survey is a strength allowing its reproducibility and the possibility of its generalization as an alternative to prevention of HIV/AIDS and other issues of reproductive health among young people in the DRC.

\subsection{On the Assessment of the Program Process}

Formative assessment took place during the intervention. It takes into account the implementation process, program execution, and it confirmed the smooth running of different stages planned for the intervention. This type of evaluation has enabled understanding the scope of the changes brought about as well as the achievement of the goals of the intervention [17]. It gave far more interest to participants' socio-demographic characteristics, to organization, the procedure, the planning of activities, the services yielded and the satisfaction of the beneficiaries. From such a viewpoint, the implication of both school managers and biology \& life education teachers was effective, regarding the structuring of the intervention in the dynamics of regular teaching. On the whole, the beneficiaries expressed their satisfaction, but they expressed a desire for the permanence of this kind of educational activity.

\subsection{On the Assessment of the Effects of the Program}

Summative assessment enables judging program efficiency, i.e. its capacity to achieve the goals set and to analyze the connection between the results achieved and the costs generated [18]. It implies questioning two aspects of reality: the measurement of changes and the attribution of changes to the intervention [13]. The assessment approach referred to the examination of the changes generated by the intervention on a client-system following the "before and after/pre and post" design. In different parts of the world, resorting to such a method has enabled-just like in the current survey-giving information on both the efficiency of sex education and teens' knowledge, attitudes, and practices with regard to HIV [19]. Indeed, the content of expected changes of evaluative studies in health education [16] [20] considers five categories of measurements of change, including 1) knowledge acquisition, 2) attitude change, 3) declared behavioral change (with or without biological control), 4) the acquisition of aptitudes to react while in a given situation, and 5) the change of a certain number of personal characteristics such as the intention to adopt a behavior, the feeling of efficiency to react, self esteem, and so forth. Globally, this study significantly determines the changes in knowledge and the improvement of attitudes in the prevention of STI/HIV and unwanted pregnancies. As for practices, they only underwent slight changes through the program. Indeed, given that the beneficiaries are at an age where sexual activity is boosted by physiological changes, the program was unable to restrain their momentum for sexual initiation. In any case, the intervention rather enabled teenagers' adherence to using condoms.

This observation is in accordance with the results of the surveys carried out in 2008 in Nigeria on the impact of sex education on high school pupils' risky behavior [21]. At the end of a 6-month intervention, sex education delayed the outset of the first sexual intercourse among non-sexually active students, but it had no effect on the sexual activity of those who had already had such an experience [21]. About a decade before, the follow-up of a 
cohort of 979 students from 17 Colorado schools with methods based on competencies revealed, after a 6-month intervention, results similar to ours. Greater knowledge of HIV, a disposition towards preventive sexual practices, and high condom use were observed without delaying or reducing the frequency of sexual relations [22]. The impact of educational interventions using quasi experimental approaches was also positively assessed as regards their methodological design [23]. In fact, the acquisition of competencies (condom usage), communication on sexuality, the reduction of risky behaviors (drop in sexual activity and sex partners) were, like in our study, visibly due to the intervention. Using "teaching methods involving the students and helping them to personalize information" was identified as one of key characteristics of the most efficient programs [24]. It is also proved that teaching based on participation and an open spirit in class entails positive attitudes towards gender equality [25]. An exhaustive survey on the impact of 22 sex education and HIV programs taught by schools in developed and developing countries showed that two thirds of programs reduce the risks linked to one or several sexual behaviors [19]. Curricula-based programs and those which are led by teachers and other adults showed strong evidence of their positive impact on declared behaviors. Such encouraging results observed in these regions entailed the extending of sex education and HIV programs in schools led by adults, including key characteristics of programs which have proved to be efficient [26].

Though the common Life Education Program is diversely taught, comparison before the intervention in the three schools showed no differences in knowledge, attitudes, and practices linked to prevention of HIV/AIDS and teenage pregnancies. And, the lack of knowledge of STI signs was globally observed in pupils in all the three schools. So, sex and HIV education needs to be promoted with participative methods, interactive discussions, and other non-didactic approaches designed to improve both the learning and the acquisition of participants' competencies to the detriment of the memorizing taking place in most schools in developing countries [27]. The efficiency and cost-effectiveness of these behavioral interventions based on competency building in schools on STI prevention to 13 - 19-year-old teens have been systematically demonstrated [28].

In our investigation, the combination of behavioral components which favor the dual prevention of STI/HIV and unwanted pregnancies was clearly enhanced in both interventions. Still, exceeding the others, intervention (PET) "B" noted a comparative advantage due to the follow-up in small groups and enabled individualizing the concerns of the teenagers interviewed.

Nevertheless, increases were also observed in the control group compared to the initial data. This fluctuation results from many factors [14], including 1) the maturation effect, i.e. changes that occur naturally in the partcipants' life with time, 2) the effects of pre-intervention tests which, on the one hand, made participants gather information and, on the other, made the control school teacher upgrade his/her teaching, and 3) the effect of losing some respondents.

Moreover, it is worth highlighting both the quality and level of training of the educator as a factor of the success of the results achieved by sex education within this survey. In another context, a sex education experience led by 16 - 17-year-old peer educators previously trained successfully used participative learning methods for sex education among 13 - 14-year-old students in England [29]. This study showed, with a randomized allocation of schools (intervention by peers versus sex education by teacher), the long-term effects of participative learning methods on 13 - 14-year-old school children's competencies. After a 7-year follow-up, the action of properly-trained peer educators entailed a fall in teenage pregnancies and enhanced competencies on sex communication, condoms use, knowledge about pregnancy, contraception, STI, and requests for health services [29].

\section{Conclusion}

Considering the human costs of unwanted pregnancies and sexually transmitted infections, including HIV, an optimization of sex and HIV education programs, particularly in schools, may provide some benefit for the development of such skills in an environment susceptible to learning [27]. The results of this study suggest that school sexual education programs can be improved to increase the quality of apprenticeship, and provide strong arguments in favor of participatory sex education focusing on the knowledge, attitudes and practices of students associated with dual prevention of STIs/HIV/AIDS and unwanted pregnancies. Given that it is unlikely that the sole general transformation of pedagogical approaches can enable by itself an improvement in adolescents' health, sex/HIV education teachers training in the use of interactive methods and discussions is a crucial step for the effective implementation of the HIV and sexuality curriculum. Nonetheless, directing education on sex education for young people based on their real needs, considering girls' and boys' specific needs, and promoting 
critical thinking skills can be beneficial for both educational outcomes and the reproductive health of adolescents.

\section{Acknowledgements}

This survey was carried out thanks to financial support provided to main Investigator by the Development Cooperation of Belgium through the Belgian Technical Cooperation—we express them our appreciation.

\section{References}

[1] United Nation Fund for Population Activities UNFPA (2011) Challenges Opportunities and Action in a World of 7 Billion. World Population Day: Of Global 7 Billion Actions Campaign in DRC.

[2] DRC Multi-Sectoral National Programme Fight against AIDS, PNMLS-DRC (2011) Epidemiological Surveillance Report of HIV/AIDS.

[3] DRC National Institute of Statistics and the United Nations Fund for Children UNICEF (2011) Multiple Indicator Cluster Survey in Democratic Republic of Congo (MICS-DRC) Final Report.

[4] DRC Ministry of Planning-MACRO (2007) Demographic and Health Survey in Demographic Republic of Congo (DHS-DRC).

[5] Rwenge, J.R.M (2013) Sexual Behavior among Adolescents and Youg People in Sub-Saharian Francophone Africa ANS Associated Factors. African Journal of Reproductive Health, 17, 49-66.

[6] Nsakala, V.G. and Coppieters, Y. (2012) Vulnerability and Risk Profiles Related to the Reproductive Health of Adolescents and Youth in the Last Decade in DRC, In Congo-Afrique, 466, 427-439.

[7] Nsakala, V.G., Coppieters, Y., Kayembe, K.P., Lapika, D.B. and Gomis, D. (2012) Adolescents' and Young People’s Perceptions of Sexual and Reproductive Health in the Democratic Republic of Congo. Revue Santé Publique, 24, 403415.

[8] Nsakala, V.G., Coppieters, Y. and Kayembe, K.P. (2013) An Innovative Approach Using Both Cellphone and Radio to Identify Young People's Sexual Concerns in the Democratic Republic of the Congo. Submit at Archives of Public Health.

[9] DRC Ministry of Primary, Secondary and Professional Education (2006) National Program for Primary et Secondary.

[10] Central Education Service to Live. Programs of Education Course to Live (2008) Primary and Secondary Level.

[11] UNESCO, UNAIDS, UNFPA, UNICEF, WHO (2009) International Technical Guidance on Sexuality Education. An Evidence-Informed Approach for Schools, Teachers and Health Educators.

[12] Lamoureux, A. (1995) Research and Methodology in Humans Sciences. Editions Etudes Vivantes, Paris.

[13] Turcotte, D. and Tard, C. (2003) The Evaluation of Intervention and the Programm Evaluation. In: Mayer, R., et al., Eds., Research Methods in Social Intervention, Gaetan Morin Editeur, Québec, 409 p.

[14] National Institute of Health and Medical Research (2003) Prevention Programs and Evaluation Methods. In: Health of Children and Adolescents. Proposal to Preserve. Les Éditions Inserm, Paris.

[15] Tones, K. (2000) Evaluating Health Promotion: A Tale of Three Errors. Patient Education and Counseling, 39, 227236. http://dx.doi.org/10.1016/S0738-3991(99)00035-X

[16] Evaluation of Health Education Programs (2001) In Education for the Health of Youngs. INSERM, Paris, 101.

[17] Lecomte, R. and Rutman, L. (1982) Introduction to Methods of Evaluative Research. Presses de l’Université Laval, Quebec.

[18] Baudouin, A., Lefrançois, R. and Ouellet, F. (1986) The Assessment Practices: Challenges, Strategies and Principles. Service Social, 35, 188-214.

[19] Kirby, D., Obasi, A. and Laris, B.A. (2006) The Effectiveness of Sex Education and HIV Education Interventions in Schools in Developing Countries. WHO Technical Report Series, No. 938, 103-150.

[20] Suchman, E.A. (1971) Evaluative Research. Russell Sage Foundation, New York.

[21] Daboer, J.C., Ogbonna, C. and Jamda, M.A. (2008) Impact of Health Education on Sexual Risk Behaviour of Secondary School Students in Jos, Nigeria. Nigerian Medical Journal, 17, 324-329. http://dx.doi.org/10.4314/njm.v17i3.37403

[22] Main, D.S., Iverson, D.C., McGloin, J., Banspach, S.W., Collins, J.L., Rugg, D.L. and Kolbe, L.J. (1994) Preventing HIV Infection among Adolescents: Evaluation of a School-Based Education Program. Preventive Medicine, 23, 409417. 
[23] Johnson, B.T., Carey, M.P., Marsh, K.L., Levin, K.D. and Scott-Sheldon, L.A. (2003) Interventions to Reduce Sexual Risk for the Human Immunodeficiency Virus in Adolescents, 1985-2000: A Research Synthesis. Archives of Pediatrics and Adolescent Medicine, 157, 381-388. http://dx.doi.org/10.1001/archpedi.157.4.381

[24] Kirby, D., Laris, B.A. and Rolleri, L. (2005) Impact of Sex and HIV Education Programs on Sexual Behaviors of Youth in Developing and Developed Countries. Youth Research Working Paper No. 2, Family Health International, Research Triangle Park.

[25] Pettersson, T. (2003) Basic Values and Civic Education, a Comparative Analysis of Adolescent Orientations towards Gender Equality and Good Citizenship. World Values Survey. http://www.worldvaluessurvey.org/wvs/articles/folder published/publication 504

[26] Ferguson, J., Dick, B. and Ross, D. (2006) Conclusions and Recommendations in Preventing HIV/AIDS in Young People: A Systematic Review of the Evidence from Developing Countries. WHO Technical Report Series No. 938. World Health Organization, Geneva.

[27] Haberland, N. and Rogow, D. (2007) Sex Education and HIV, It Is Time to Change in Methodology. Promote the Health, Safety and Productivity. Transitions to Adulthood. Document $n^{\circ} 22$.

[28] Shepherd, J., Kavanagh, J., Picot, J., Cooper, K., et al. (2010) The Effectiveness and Cost-Effectiveness of Behavioural Interventions for the Prevention of Sexually Transmitted Infections in Young People Aged 13 - 19: A Systematic Review and Economic Evaluation. Health Technology Assessment, 14, 1-206, iii-iv.

[29] Stephenson, J., Strange, V., Allen, E., Copas, A., et al. (2008) The Long-Term Effects of a Peer-Led Sex Education Programme (RIPPLE): A Cluster Randomized Trial in Schools in England. PLoS Medicine, 5, e224. 